ISSN: 0213-2079 - ISSN electrónico: 2386-3889

DOI: https://doi.org/10.14201/shhmo20173922752

\title{
ANTES DE 1717: LA CASA DE LA CONTRATACIÓN EN EL CÁDIZ DEL SEISCIENTOS*
}

\section{Before 1717: The Casa de la Contratación in Seventeenth Century Cadiz}

José Manuel DÍAZ BLANCO

Universidad de Sevilla

Correo-e: diazblanco@us.es

RESUMEN: Este artículo analiza la presencia de la Casa de la Contratación en Cádiz durante el siglo Xvir, antes de la publicación del decreto de 1717 que ordenaba su traslado desde Sevilla. Tres elementos se destacan: el servicio permanente del Juez de Indias, las estancias en Cádiz que los ministros de Sevilla realizaban todos los años y la competencia institucional entre unos y otros. Se concluye así que la Casa de la Contratación participó en el desarrollo de Cádiz durante el siglo xvir y que el decreto de 1717 debe entenderse como una culminación de este proceso.

Palabras clave: Casa de la Contratación; Juzgado de Indias de Cádiz; Rivalidad portuaria Sevilla-Cádiz; Conflictividad institucional; Cádiz (siglo XVII).

ABSTRACT: This paper analyzes the presence of the Casa de la Contratación (House of Trade) in Cadiz during the seventeenth century, before the publication of the royal decree of 1717 ordering its transfer from

* Proyecto ANDATLAN «Andalucía en el mundo atlántico: actividades económicas, realidades sociales y representaciones culturales (siglos XVI-XVIII)», HAR2013-41342-P, financiado por el Ministerio de Economía y Competitividad del Gobierno de España. Agradezco al profesor Juan José Iglesias Rodríguez la invitación para participar en este dossier y su ayuda para mejorar el texto del artículo. 
JOSÉ MANUEL DÍAZ BLANCO

ANTES DE 1717: LA CASA DE LA CONTRATACIÓN EN EL CÁDIZ DEL SEISCIENTOS

Seville to this city. In it, I highlight three facts: the permanent service of the Juez de Indias (Judge of Indies), the stages in Cadiz that ministers from Seville performed every year, and the institutional competition between the Judge and the ministers. I conclude that the Casa de la Contratacion participated in the rise of Cadiz along the seventeenth century, which is why the decree of 1717 must be understood as a culmination of this process.

Key words: Casa de la Contratación (House of Trade); Cadiz Juzgado de Indias (Judge of Indies of Cadiz); Institutional Conflict; Seville-Cadiz Port Rivalry; Cadiz (Seventeenth Century).

Cuando en 1680 la cabeza de línea de las flotas vuelve a Cádiz, ya no es un simple antepuerto, sino un rival, lo que Sevilla se encuentra frente a sí. Desposeída desde mucho tiempo antes desde el punto de vista marítimo, ahora es amenazada desde el punto de vista comercial, y no se mantiene más que por la preeminencia administrativa: es siempre en ella donde reside la Casa de Contratación y el Consulado. No queda más para completar la victoria de Cádiz que arrebatárselos a Sevilla. Y es lo que Cádiz va a perseguir en adelante y lo que llegará a conseguir a comienzos del siglo XVIII.

Albert Girard (1932)

En la historia del comercio andaluz, 1717 es señalado como uno de los hitos principales. Sin duda, el traslado a Cádiz de la Casa de la Contratación y el Consulado de Cargadores acredita tan merecida reputación. No obstante, la comprensión de estos acontecimientos requiere una perspectiva amplia. Hay que evitar el peligro de pensar la efeméride como un suceso aislado, pues no fue sino el punto cenital de un proceso a través del cual Cádiz arrebató a Sevilla la primacía comercial de la región a lo largo del siglo xvir. Esta premisa goza de una aceptación amplia, por no decir unánime, desde largo tiempo atrás. Baste recordar a Antonio Domínguez Ortiz, apasionado estudioso de estas materias, que en su Orto y ocaso de Sevilla (1946) lamentaba el evento como una «fecha funesta para nuestra ciudad», y advertía: «tan trascendental medida tuvo una larga gestación, cuyas principales etapas importa fijar» ${ }^{1}$.

Esa labor ya había sido realizada por un historiador francés. Se trataba de Albert Girard, que había publicado en 1932 un libro maravilloso titulado La rivalidad

1. Domínguez Ortiz, A.: Orto y ocaso de Sevilla. Sevilla, 1991 [1946], p. 142. 
comercial y marítima entre Sevilla y Cádiz hasta finales del siglo XVIII. Girard creó un modelo explicativo que descomponía el problema en tres facetas: la náutica, la comercial y la institucional. El punto más sensible de la teoría radicaba en cómo vincularlas. Todas habían sido importantes, pero Girard entendía que durante el siglo xvir las dos primeras habían ejercido una responsabilidad superior en el fortalecimiento de la posición gaditana, merced a la degradación del Guadalquivir como vía navegable y a la preferencia de los comerciantes por la bahía, donde encontraban más libertad y menos impuestos que en la vieja capital. El traslado de las instituciones ocurrió después, en el famoso 1717, cuando los órganos de gobierno que aún residían en Sevilla asumieron los hechos consumados ${ }^{2}$.

Domínguez Ortiz reprodujo bastante fielmente la pauta propuesta por Girard: «el desplazamiento del tráfico marítimo llevó consigo el de las mercaderías, y, finalmente, el de los funcionarios». El orden de los factores parecía establecido, pero convenía aclararlo y matizar. Antes del desplazamiento definitivo en 1717, aquellos «funcionarios» ya habían pisado la ciudad. De hecho, la habían pisado con frecuencia, «pues si bien los organismos oficiales continuaban residiendo en Sevilla, tuvieron que enviar, primero con carácter ocasional, y luego permanentemente, personal a Sanlúcar y Cádiz, para vigilar las operaciones que en estas ciudades se verificaban» ${ }^{3}$. Aunque la sede oficial de la Casa y el Consulado continuase instalada en Sevilla, muchos de sus ministros se habían desplazado a Cádiz ya en el siglo xvir, cuando no antes. Al igual que los barcos y los comerciantes. Por supuesto, la historiografía mejor conocedora del Cádiz barroco le daría la razón a Domínguez Ortiz, y no se sorprendería en absoluto por su afirmación. Así, Manuel Bustos Rodríguez ha confirmado en un trabajo reciente que la ciudad «había conseguido de las autoridades el derecho a un Juzgado y Tabla de Indias, que posibilitaba la salida de barcos con rumbo a América, supervisados por agentes de Sevilla desplazados periódicamente hasta Cádiz» ${ }^{4}$.

2. GIRARD, A.: La rivalidad comercial y marítima entre Sevilla y Cádiz hasta finales del siglo XVIII. Antonio García-Baquero, ed., Sevilla, 2006 [1932]. La cita destacada en el encabezamiento del artículo procede de esta obra, en p. 114.

3. Domínguez Ortiz: Orto y ocaso, pp. 143-144. No obstante, siempre existía la tentación de subrayar el retraso institucional como idea fundamental: «En estas circunstancias, no debe extrañarnos que la Casa fuera transferida a Cádiz, sino que tardara la Administración medio siglo en decidirse a esta medida, pues estando radicada la mayoría del comercio en Cádiz parecía lógico que los organismos administrativos correspondientes también lo estuvieran»: Domínguez Ortiz, A.: «La burguesía gaditana y el comercio de Indias desde mediados del siglo Xvir hasta el traslado de la Casa de Contratación», en La burguesía mercantil gaditana (1650-1868). Cádiz, 1976, pp. 3-11.

4. Bustos Rodríguez, M.: «Cambio político y comunidades mercantiles: los flamencos de Cádiz tras la Paz de Utrecht», en Iglesias Rodríguez, J. J. y García Bernal, J. (coords.): 
Esta investigación se propone retomar estas reflexiones y continuar trabajando la idea de que el ascenso de Cádiz en el siglo xvir no fue ajeno al plano institucional. No es cierto que solo los comerciantes participaran en él, como pudiera suponer una evolución excesivamente restrictiva del modelo Girard. En ocasiones, puede resultar tentador escribir una historia del comercio despolitizada. Determinadas pautas de análisis, muy en boga durante los últimos tiempos -los análisis de redes, por ejemplo-, pueden dirigirnos hacia este punto de vista, donde lo que más importa es escrudiñar las conexiones entre personas particulares: en este caso, los mercaderes y sus diferentes círculos sociales y profesionales ${ }^{5}$. No obstante, el comercio no es solo de los comerciantes. Había un universo inagotable dentro y alrededor de él, en el que los poderes políticos y sus representantes ocupaban un puesto de indudable relevancia ${ }^{6}$. La Carrera de Indias fue un sistema marítimo y comercial fuertemente institucionalizado, y su evolución no puede entenderse soslayando esta dimensión ${ }^{7}$. La Casa se dio cuenta perfectamente de la importancia de los «puertos», y de Cádiz en particular, bastante antes de 1717. Y actuó en consecuencia, potenciando paulatinamente su presencia allí.

La proyección de la Casa en el Cádiz seiscentista presentaba una dimensión doble. Por una parte, tenía lugar a través de oficiales que actuaban de manera permanente, entre los cuales sobresale el famoso juez de Indias de Cádiz, cuyo periplo histórico nos remite cronológicamente al XVI antes que al propio XVII. A su lado, proliferaron paulatinamente (ahí ya sí en el xvir sobre todo) ministros y oficiales con comisiones específicas y temporales en la bahía, fundamentalmente relacionadas con la preparación de las flotas y armadas de la Carrera de Indias o con su control fiscal. En la época, aquello se llamaba ir o bajar a los puertos, y lo

Andalucía en el mundo atlántico. Agentes y escenarios. Madrid, 2016, pp. 311-333 (la cita en página 313).

5. El estudio de los mercaderes gaditanos ha generado en los últimos años trabajos realmente excelentes, entre los cuales se concede al siglo XVIII una prioridad justificada, aunque para el XVII existen títulos como CARRAsco GonzÁLEZ, G.: Los instrumentos del comercio colonial en el Cádiz del siglo XVII (1650-1700). Madrid, 1996 y Comerciantes y casas de negocios en Cádiz (1650-1700). Cádiz, 1997; Bustos Rodríguez, M.: Cádiz en el sistema atlántico. La ciudad, sus comerciantes y la actividad mercantil (1650-1830). Madrid, 2005.

6. Por otro lado, resulta completamente evidente la porosidad histórica entre categorías conceptuales aparentemente claras como las de comerciantes, marinos u oficiales reales, según demuestran numerosos estudios explícita o implícitamente. Véanse, entre muchos otros ejemplos posibles, Teijeiro, J. M.: Cargadores de Indias y marinos. Los La Rosa. Cádiz, 2005; Herrero GIL, M. D: El mundo de los negocios de Indias. Las familias Álvarez Campana y Llano San Ginés en el Cádiz del siglo XVIII. Sevilla, 2013.

7. Se me disculpará que, para una historia política de la Carrera de Indias en el siglo XviI, remita a Díaz Blanco, J. M.: Así trocaste tu gloria. Guerra y comercio colonial en la España del siglo XVII. Madrid, 2012. 
JOSÉ MANUEL DÍAZ BLANCO

ANTES DE 1717: LA CASA DE LA CONTRATACIÓN EN EL CÁDIZ DEL SEISCIENTOS

hicieron numerosos ministros de la Casa, que servían en Cádiz durante meses y, a veces, durante años.

Esta doble dimensión cabe ser vista como una manifestación particular del problema general que Juan Francisco Pardo Molero y Manuel Lomas Cortés explicaron en un magnífico libro dedicado a los oficiales reales de la Monarquía. Entre el cúmulo de ideas abordado en la obra, resulta especialmente útil a los efectos presentes la distinción entre los gobiernos ordinario y extraordinario en la Edad Moderna. Bebiendo del pensamiento de Otto Hintze sobre la materia, Pardo y Lomas razonan que en la España Moderna convivieron ambos modelos, debido a la proliferación de comisarios y delegados especiales que actuaban en cualquier territorio con relativa o completa autonomía de los poderes locales permanentes. Naturalmente, esta estrategia administrativa era una fuente potencial de conflictos frecuentes. Si se insistía en ella, al punto de convertir lo extraordinario en ordinario, era porque servía para fortalecer el poder absoluto de la Monarquía, amparada bajo el ubicuo discurso de la necesidad ${ }^{8}$.

Con sus matices particulares, pues no hay dos casos iguales, la proyección gaditana de la Casa reproducía esta dualidad institucional. Los jueces de Cádiz ocupaban la posición del gobierno ordinario y los jueces sevillanos que bajaban a los puertos, el gobierno extraordinario. Este enfoque nos permite añadir nuevos elementos a la competitividad entre Sevilla y Cádiz. No se trata de pensar que unos y otros estuvieran siempre a la gresca. De hecho, no fue así. Hasta resulta notorio que algunos jueces gaditanos mantuvieron excelentes relaciones con sus colegas de Sevilla. Sin embargo, también hubo etapas y momentos de patente confrontación. Y si eso es consustancial a todas las esferas de poder y se explica desde la óptica del conflicto portuario amplio, tal como tantas veces se nos ha presentado (Sevilla intentando mantener sus privilegios tradicionales y Cádiz intentando heredarlos); también cabría interpretarse como una pugna por dirimir quién mandaba en los puertos de la bahía, de los que ya no se podía prescindir?.

* * *

8. Pardo Molero, J. F. y Lomas Cortés, M. (coords.): Oficiales reales. Los ministros de la Monarquía Católica. Valencia, 2012, especialmente la introducción y los excelentes capítulos del mismo Lomas y Rafael Benítez Sánchez-Blanco.

9. También se podría insertar el problema en el marco de la conflictividad barroca, temática de amplia bibliografía, con títulos recientes como Lozano Navarro, J. y Castellano, J. L. (coords.): Violencia y conflictividad en el universo barroco. Granada, 2010; IgLesias, J. J. y López-Guadalupe, M. L. (coords.): Realidades conflictivas. Andalucía y América en la España del Barroco. Sevilla, 2012. 
El Juzgado de Indias fue un oficio tan representativo del Cádiz moderno que puede parecer un cargo puramente municipal, estrictamente vinculado a la ciudad. Sin embargo, el juez de Indias era un ministro de la Casa de la Contratación. Se le llamaba juez como a los demás «jueces oficiales» que residían en Sevilla, solo que vivía y trabajaba en Cádiz y otras localidades costeras. Era el juez de la Casa de la Contratación que residía en Cádiz, como refleja la documentación cuando desarrolla esa expresión abreviada de juez de Indias de Cádiz. Las posibles confusiones que pueda haber al respecto se deben en parte a una bibliografía menor de lo que merecería un oficio tan relevante, cuyo conocimiento urge potenciar con nuevas investigaciones ${ }^{10}$.

La plena pertenencia del juez gaditano a la Casa de la Contratación no admite dudas. La demuestran fehacientemente la inclusión de sus títulos en los libros de provistos de la Casa ${ }^{11}$, así como la concurrencia de los titulares en las nóminas de salarios de la institución, elaboradas por los tesoreros de la Casa y supervisadas por la Contaduría del Consejo de Indias ${ }^{12}$. Los registros son muy numerosos y su lectura sistemática no hace sino corroborar constantemente lo que se observa tras las primeras lecturas. En última instancia, por si hiciera falta alguna prueba más, lo reiteran los textos legales sancionados o comentados en la Recopilación de Leyes de Indias y el Norte de la Contratación de José de Veitia Linaje ${ }^{13}$.

La Recopilación aglutinaba un conjunto de disposiciones emitidas a partir de 1535, cuyo mensaje central advertía:

10. Los aspectos básicos sobre el tema fueron planteados por Haring, C. H.: Comercio y navegación entre España y las Indias. México, 1979 [1918] y GIRARD: La rivalidad, pero es evidente que hacen falta visiones renovadas y monográficas. Agradezco a los profesores Manuel Bustos Rodríguez y Juan José Iglesias Rodríguez su asesoramiento a la hora de realizar esta valoración bibliográfica.

11. Archivo General de Indias [en adelante AGI], Contratación, legs. 5.784-5.786.

12. AGI, Contaduría, legs. 338a, 346a, 348, 349, 352b, 353, 355a, 356a, 358, 362a, 364, 369b, 373a, 375a, 379, 384a, 386a, 389, 390, 392, 397, 400. Pese a la abundancia de la documentación (estos legajos se refieren exclusivamente al siglo XVII), debe advertirse contra la pretensión de reconstruir perfectamente la nómina de jueces de Indias solo a través de las nóminas salariales, en primer lugar por su considerable empeoramiento informativo durante las últimas décadas del XVII (en paralelo al deterioro de las rentas reales con las que la Casa abonaba salarios a su gente) y, en cualquier caso, por las frecuentes situaciones ambiguas que reflejan, muy propias de la Edad Moderna (que ejerciera y cobrara el teniente en vez del titular, que un padre y un hijo negociaran un cobro combinado...).

13. Recopilación de Leyes de los Reinos de Indias [en adelante RLRI], citado según la magnífica edición de México, 1987, que reproduce facsimilarmente la edición princeps de Madrid, 1681, lib. 9, tít. 4; Veitia Linaje, J. de: Norte de la Contratación de las Indias Occidentales. Sevilla, 1672, lib. 1, cap. 25. 
JOSÉ MANUEL DÍAZ BLANCO

ANTES DE 1717: LA CASA DE LA CONTRATACIÓN EN EL CÁDIZ DEL SEISCIENTOS

Ordenamos, y mandamos, que en la Ciudad de Cadiz haya vn Iuez Oficial, que resida en ella, y entienda solamente en recevir las [sic] Navios, que llegaren de las Indias, y á sus dueños, Capitanes, y Maestres se les huviere concedido facultad de tomar aquel Puerto, y descargar en él: y asimismo en el despacho de los dichos Navios, personas, y mercaderías, que en ellos vinieren, y no en determinar pleitos, ni causas algunas entre partes, porque de esto han de conocer el Presidente, y Iuezes de la Casa de Contratacion de Sevilla, como por estas leyes se determina; excepto en lo que expresamente le estuviere concedido por $\mathrm{Nos}^{14}$.

Desde el principio se determinaban los ámbitos jurisdiccionales. El juez de Cádiz entendía en la visita y el apresto de los navíos de la Carrera de Indias, pero a diferencia de sus colegas sevillanos carecía de responsabilidades judiciales, a no ser que el monarca ordenase lo contrario en momentos específicos.

Las calidades del juez gaditano nos remiten a un conjunto de valores que solía exigirse en la mayoría de los ámbitos del gobierno real. Se le requería que fuese «hábil, y suficiente, y de la buena conciencia, y fidelidad, que para el exercicio se requiere». Difícilmente podía ser de otra manera, evidentemente. Las tareas que estaban puestas bajo su responsabilidad no eran pequeñas, como no era pequeña tampoco su dignidad institucional. Los demás jueces de la Casa estaban obligados a respetar su espacio de poder (y viceversa); tenía capacidad para nombrar alguaciles que cubrieran sus ausencias o atendieran a navíos que hubiesen arribado a algún punto lejano, todos a sus órdenes; era independiente en materias de Indias de las justicias generales de Cádiz, como el corregidor, el alcalde mayor o sus lugartenientes; y los generales y almirantes de la Carrera no podían impedirle el desempeño de sus funciones, ni siquiera en la visita de los navíos que estaban a su mando. Su preeminencia era notable, por tanto, y antes que subordinarse a nadie, debía estar en contacto con todo el mundo, especialmente con sus compañeros de Sevilla. El juez, con la ayuda de un escribano propio, debía escribirlo todo y compartir la información con la Casa, pudiendo librar al receptor de la avería los gastos necesarios para pagar el correo. Todo para que los navíos de Cádiz se visitasen y despachasen igual que los que salían de Sevilla. Y para que, efectivamente, ningún barco saliese del Puntal sin contar con la licencia del señalado ministro ${ }^{15}$.

Ahora bien, más allá de las disposiciones normativas y de la retahíla de privilegios y obligaciones, ¿quiénes fueron realmente aquellos hombres presuntamente hábiles, suficientes, fieles y de buena conciencia? Una respuesta plenamente satisfactoria para esta pregunta requeriría mucho más espacio del que es posible

14. RLRI, lib. 9, tít. 4, ley 1 .

15. Estas explicaciones conjugan los contenidos de varias de las leyes contenidas, nuevamente, en $R L R I$, lib. 9 tít. 4 . La cita proviene de la ley 2. 
dedicarle aquí. No obstante, es posible trazar algunas pinceladas que nos iluminen, siquiera, aspectos parciales. Habría que empezar por la propia identidad de los jueces de Cádiz, cuya sucesión puede reconstruirse con razonable exactitud a partir de la documentación interna de la Casa antes mencionada: los libros de provistos y las nóminas de tesorería.

Cuadro 1. Jueces de Indias en Cádiz durante el siglo xviI

$\begin{array}{ll}\text { Pedro del Castillo } & {[1600]-1604} \\ \text { Juan Bautista de Baeza } & 1604-1615 \\ \text { Francisco Ruiz y Polanco } & 1615-1623 \\ \text { Juan Antonio Ruiz y Polanco } & 1624-1638 \\ \text { Jerónimo Rodríguez de Rozas } & 1638-1659 \\ \text { Pedro Fernández Moreno* } & 1639-1654 \\ \text { Bartolomé Fernández Moreno* } & 1654-1659 \\ \text { Juan Ignacio Ruiz [o de Baeza] y Polanco } & 1659-1663 \\ \text { Pedro Jiménez de Guzmán } & 1660 *-1684 \\ \text { Pedro de Román y Soto } & 1684-[1700]\end{array}$

Fuente: AGI, Contaduría (cuentas de tesoreros) y Contratación (libros de provistos). * tenencia / interinidad.

La repetición de ciertos apellidos como Baeza o Polanco no es casual. Obedece a una transmisión del oficio por vía familiar. La práctica era harto común en la administración real de los Austrias y, de hecho, se daba con bastante frecuencia entre los oficios de la Casa de la Contratación ${ }^{16}$. No hay que entenderla necesariamente como el fruto de una patrimonialización stricto sensu. No se trataba tanto del traspaso de una propiedad privada entre un padre y un hijo o cualquier otro heredero. Más bien, respondía a la realidad de una herencia de méritos. Los sucesores se beneficiaban de los que habían acumulado sus antecesores durante una vida de servicio al rey y este lo reconocía manteniendo el oficio en el mismo ámbito dinástico.

16. Díaz Blanco, J. M.: «Servicio al rey y progreso social en el siglo xvir: los oficiales de la avería en la Casa de la Contratación», en García Hernán, E. y MAfFi, D. (coords.): Estudios sobre guerra y sociedad en la Monarquí Hispánica. Guerra maritima, estrategia, organización y cultura militar (1500-1700). Valencia, 2017, pp. 471-492. 
Esta lógica predominó hasta que la venalidad afectó al oficio, como a los demás de la $\mathrm{Casa}^{17}$. El primero que pagó por ser juez de Indias fue Jerónimo Rodríguez de Rozas, caballero de la orden de Santiago, quien abonó la suma de 10.000 ducados en 1638, tras la muerte de Juan Antonio Ruiz y Polanco ${ }^{18}$. La viuda de este reaccionó tan pronto como pudo y trató de reservar la sucesión a sus hijos, recordando al rey los servicios familiares pasados, pero añadiéndole el desembolso de 40.000 reales $^{19}$. El beneficiario fue Juan Ignacio Ruiz y Polanco, que no se incorporó al oficio hasta 1659 e inmediatamente nombró como teniente a Pedro Jiménez de Guzmán, regidor perpetuo de Cádiz. Este, a su vez, pagó a la Corona 5.500 ducados de plata y a cambio consiguió que se le reservara el oficio para sí tras la muerte del titular, con la capacidad adicional para designar como sucesor a uno de los dos nietos de su esposa cuando cumplieran veinticinco años ${ }^{20}$. Los favorecidos eran los dos hermanos Román y Soto, aunque la muerte de uno de ellos allanó el camino al otro, Pedro, a quien la vida sonrió sin ambages: juez de Indias y caballero de Calatrava ${ }^{21}$.

Dos factores contribuyeron así a que el Juzgado de Indias de Cádiz se alejara de las redes de poder sevillanas y se acercara a las de Cádiz: el paso del tiempo y el dinero. Los Baeza-Polanco fueron un linaje de origen hispalense que logró mantener buenas conexiones con la Casa durante décadas. En cambio, los Jiménez de Guzmán y los Román y Soto estaban mucho más identificados con Cádiz, sus instituciones y sus intereses. Nada de lo cual resultó irrelevante en las disputas por el poder que tuvieron lugar entre la Casa, el Juzgado de Indias y el Cabildo gaditano durante la segunda mitad del siglo xvII, como después veremos.

$$
* * *
$$

17. Schäfer, E.: El Consejo Real y Supremo de las Indias. Historia y organización del Consejo y de la Casa de Contratación de las Indias. Valladolid, 2003 [1935-47], I, pp. 311-317; García-Baquero González, A.: La Carrera de Indias: suma de la contratación y océano de negocios. Sevilla, 1992, pp. 65-67; AndúJar CASTILlo, F.: «La Casa de Contratación y la venalidad de los cargos (1634-1717)», en NúÑ̃z, F. y GAMERO, M. (coords.): Entre lo real y lo imaginario. Sevilla, 2014, pp. 47-73.

18. AGI, Contratación, leg. 5.785, lib. 1, fols. 143v-145v; título, Madrid, 15 de julio de 1638.

19. AGI, Contratación, leg. 5.785, lib. 2, fol. 109r-114v; nombramiento, 1659.

20. AGI, Contratación, leg. 5.785, lib. 2, fols. 126v-129r, teniente de juez de Indias, 1660; fols. 131v-132r, futura de juez de Indias, 1660; fols. 158v-161v, nombramiento como juez de Indias, 1663.

21. AGI, Contratación, leg. 5.785, lib. 3, fols. 132r-136r; nombramiento de Pedro de Román y Soto, 1684 (aunque el expediente contiene copia de documentos de 1679, que demuestran que justo cuando el Cabildo de Cádiz lograba la reaparición del Juzgado de Indias, el regidor perpetuo Pedro Jiménez de Guzmán aprovechaba para nombrar sucesor a Pedro, que no tomó posesión hasta 1684). 
Raimundo de Lantery recordaba que en los tiempos en los que se preparaba la flota de don Pedro Corbet «las cosas de Indias andaban en gran estimación y estaba Cádiz en su mayor lustre». A aquel fino observador de la ciudad seiscentista no se le escapó la presencia de don Gonzalo Fernández de Córdoba, presidente de la Casa de la Contratación, que «entonces estaba en Cádiz atendiendo al despacho de la flota del dicho don Pedro Corbete para la Nueva España». Recorriendo las fascinantes páginas de sus memorias, comprobamos que tampoco le pasó desapercibida la concurrencia de Francisco Antonio de San Millán, Juan Jiménez de Montalvo, el marqués de Narros, Pedro de Oreitia, el conde de Montellano y algunos otros más 22 .

Las anotaciones de Lantery aludían a algo más profundo que la mera rapidez anecdótica. Conforme avanzaba el siglo xviI, se hizo cada vez más frecuente que los principales ministros de la Casa de la Contratación residieran largas temporadas en Cádiz. A menudo, cuando repasamos las nóminas de los jueces oficiales (empezando por la de Schäfer, ya casi centenaria), no pensamos en esta circunstancia. Damos por hecho que se encontraban en Sevilla - ¿dónde si no?-, ejerciendo sus responsabilidades cerca del Guadalquivir, en la zona neurálgica comprendida entre el Arenal y los Reales Alcázares. Ignoramos u olvidamos entonces las estancias gaditanas de aquellos hombres, que tendieron a alargarse cada vez más, así como a rondar mucho más la bahía que Sanlúcar y la desembocadura del río. Durante meses, el presidente de la Casa de la Contratación se encontraba en Cádiz, y no en Sevilla. Y lo mismo podía decirse de muchos de los ministros más destacados, entre los jueces oficiales tradicionales y los de creación posterior. Es más, no cabe duda de que la ampliación de la plantilla de la Casa a lo largo del xvir se debió en buena parte al incremento de la actividad fuera de Sevilla, en Cádiz ${ }^{23}$.

La Recopilación dedica un título entero a esa realidad de bajarse a los puertos ${ }^{24}$, pero su carácter práctico cotidiano se halla mucho mejor reflejado en el Norte de

22. Bustos Rodríguez, M. (ed.): Un comerciante saboyano en el Cádiz de Carlos II (Las memorias de Raimundo de Lantery, 1673-1700). Cádiz, 1983.

23. Desde Schäfer, el crecimiento de oficios se ha relacionado con la dinámica de ventas iniciada en tiempos de Felipe IV. CÉsPEDES DEL CASTILLO, G.: La avería en el comercio de Indias. Sevilla, 1945, lo relacionó también con el incremento de competencias a partir de la creación del sistema de flotas y armadas. En esta misma línea, considero necesario tener presente también la creciente necesidad de acudir a los puertos a lo largo del siglo Xvir.

24. RLRI, lib. 9, tít. 5, «Del Iuez Oficial, y Consul, que ván á los Puertos al despacho de las Flotas, y Armadas». La Recopilación refiere al cónsul junto al juez oficial porque el Consulado también adoptó la costumbre de enviar a alguno de sus ministros a Cádiz durante el siglo XviI, una realidad que podría analizarse con la misma metodología que se usará aquí para estudiar a los jueces de la Casa a través de los epistolarios del tribunal mercantil conservados en la sección Consulados. 
la Contratación. Veitia, de hecho, escribía a partir de la experiencia. Él mismo, durante sus años de servicio en la tesorería, pasó una prolongada estancia en Cádiz que duró un año aproximadamente, desde fines de 1661 a fines de 1662. Como puede suponerse, períodos tan dilatados realizando arduos trabajos lejos del centro del poder institucional y de la residencia habitual agradaban poco a los ministros de la Casa. Una de las primeras cosas que Veitia reconocía era que «el turno destos despachos siempre se ha tenido por el mayor gravamen destas ocupaciones, por cuya causa se halla que repetidas vezes han intentando escusarse del los Iuezes» ${ }^{25}$. Él mismo hizo todo lo posible por no repetir y, de hecho, lo consiguió. Según reconocía con satisfacción, logró escurrir el bulto en 1667, pese a que los precedentes no lo favorecían ${ }^{26}$.

Entre quienes se desplazaban a Cádiz por cuestión de días o escasas semanas, siempre figuraban uno, dos o tres ministros de la Casa que permanecían allí meses o, más adelante, años. ¿Cómo reflejar esta realidad? Existe una fuente documental fascinante que aún no ha sido suficientemente explotada por la historiografía y puede emplearse para tales fines. Se trata de los epistolarios gaditanos que estos hombres escribían. Su interlocutor no era el Consejo. Ellos no escribían a Madrid. El interlocutor era la propia Casa de la Contratación, a la que escribían de manera continua, con una periodicidad que roza un nivel óptimo para los canales oficiales de comunicación en el siglo Xvir. Por no abandonar el caso de Veitia Linaje, resulta que en aquellos doce meses escribió más de doscientas cartas solo a sus colegas de Sevilla. Su caso no es excepcional, sino uno más que demuestra los generosos contenidos de estos epistolarios. Hay muchos modos posibles de utilizarlos ${ }^{27}$. El más evidente pasa por trabajarlos como fuentes directas de información, con las que reconstruir los preparativos y los recibimientos de las armadas y flotas. Pero, entre otras posibilidades, se encuentra la que aquí seguiremos: utilizar los epistolarios a modo de localizadores, a fin de delimitar las estancias gaditanas de los ministros de la Contratación.

Aunque esta técnica no se haya aplicado nunca a esta documentación en concreto, se basa en una metodología bien conocida entre muchos estudiosos. La

25. Veitia Linaje: Norte de la Contratación, lib. 1, cap. 8 (la cita en p. 54).

26. Idem, p. 55. Aunque en realidad sí llegó a desplazarse a Sanlúcar, puesto que allí firmó la hoja genealógica que presentó para obtener su hábito de Santiago: Archivo Histórico Nacional, Órdenes Militares, Santiago, exp. 945. Después, tuvo que desplazarse de nuevo a Sanlúcar en 1674, pero apenas permaneció allí unas semanas y da la impresión de que fue sustituido por Alonso de Baeza y Mendoza: AGI, Contratación, leg. 5.130.

27. El género epistolar ha sido densamente estudiado en las últimas décadas. Ofrece una buena síntesis conceptual y bibliográfica: Schulte, R. y Tippelskirch, X. V. (eds.): Reading, Interpreting and Historicizing: Letters as Historical Sources. Florencia, 2004. 
correspondencia interna de la Casa, como era habitual en los ámbitos institucionales (y también en los privados), solía fecharse. Esto es, se indicaba el lugar y el día en el que se había escrito (o terminado de escribir en el caso de epístolas muy extensas y trabajadas, circunstancia que aquí no solía tener lugar). Quien no haya manejado nunca este tipo de documentación tal vez desconozca la exactitud que pueden presentar las datas epistolares. A veces, se refleja en el aspecto temporal, indicando incluso la hora en la que fueron firmadas, pero con mayor frecuencia se comprueba en la dimensión espacial, donde los firmantes eran absolutamente precisos.

Por tanto, una carta sitúa a quien la escribe en un lugar y un momento determinados. Solo eso puede ser precioso para la ciencia histórica en más de una ocasión. Sin embargo, si se tiene la fortuna de poseer, no una, sino muchas cartas -una serie de cartas-, surge una oportunidad para ir más allá: reconstruir la secuencia de movimientos de una persona durante un período de tiempo más o menos prolongado. $\mathrm{Y}$, al fin, eso es lo que nos proponemos aquí. Utilizar los fantásticos conjuntos epistolares que escribieron a Sevilla para medir cronológicamente las estancias y los movimientos de los ministros de la Casa en el entorno de la bahía. ¿Puede hacerse? La respuesta es afirmativa, con todas las precauciones que prudentemente queramos expresar. Como es obvio, no todos los epistolarios se conservan en las mismas condiciones (ahí entran en juego infinidad de imponderables) ni todos los oficiales eran igual de diligentes a la hora de escribirlos: algunos hasta fechaban las cartas en el navío desde donde escribían, mientras otros se limitaban a fechar en la «bahía» en cuanto salían de Cádiz. Pese a tales diferencias, prácticamente siempre encontramos una calidad documental más que suficiente para emprender el análisis propuesto.

Podría decirse más; de manera relativamente frecuente, surge la posibilidad de realizar un estudio mucho más refinado del que aquí, por razones de espacio, puede recogerse. En muchos casos, podría trazarse un conjunto de idas y venidas sumamente preciso entre localidades de la provincia gaditana, a través de un espacio que justo por aquellas fechas aparecía parcialmente representado en el colosal Emporio del Orbe de fray Jerónimo de la Concepción ${ }^{28}$. Las referencias más habituales eran Cádiz, Sanlúcar de Barrameda, El Puerto de Santa María y Puerto Real. Ocasionalmente, se mencionaban Rota, Jerez de la Frontera, Bonanza y la Carraca. Y con cierta frecuencia se hablaba de la bahía en términos generales, no solo por dejadez, sino también por no encontrarse el autor en ningún

28. En el mapa llamado Insula Gaditana, publicado originalmente en Concepción, J. de la: Emporio del Orbe, Cádiz ilustrada. Ámsterdam, 1690, que se reproduce en estas páginas a través de la reproducción digital realizada sobre el ejemplar de la Biblioteca de la Universidad de Sevilla, Fondo Antiguo, A 25(b)/268. 
punto concreto de tierra o embarcado de Puntales adentro ${ }^{29}$. Por supuesto, estas referencias no eran excluyentes entre sí. Pueden encontrarse cartas fechadas en un navío surto en el puerto de Bonanza en Sanlúcar; o en la bahía, yendo entre Puerto Real y El Puerto, etc.

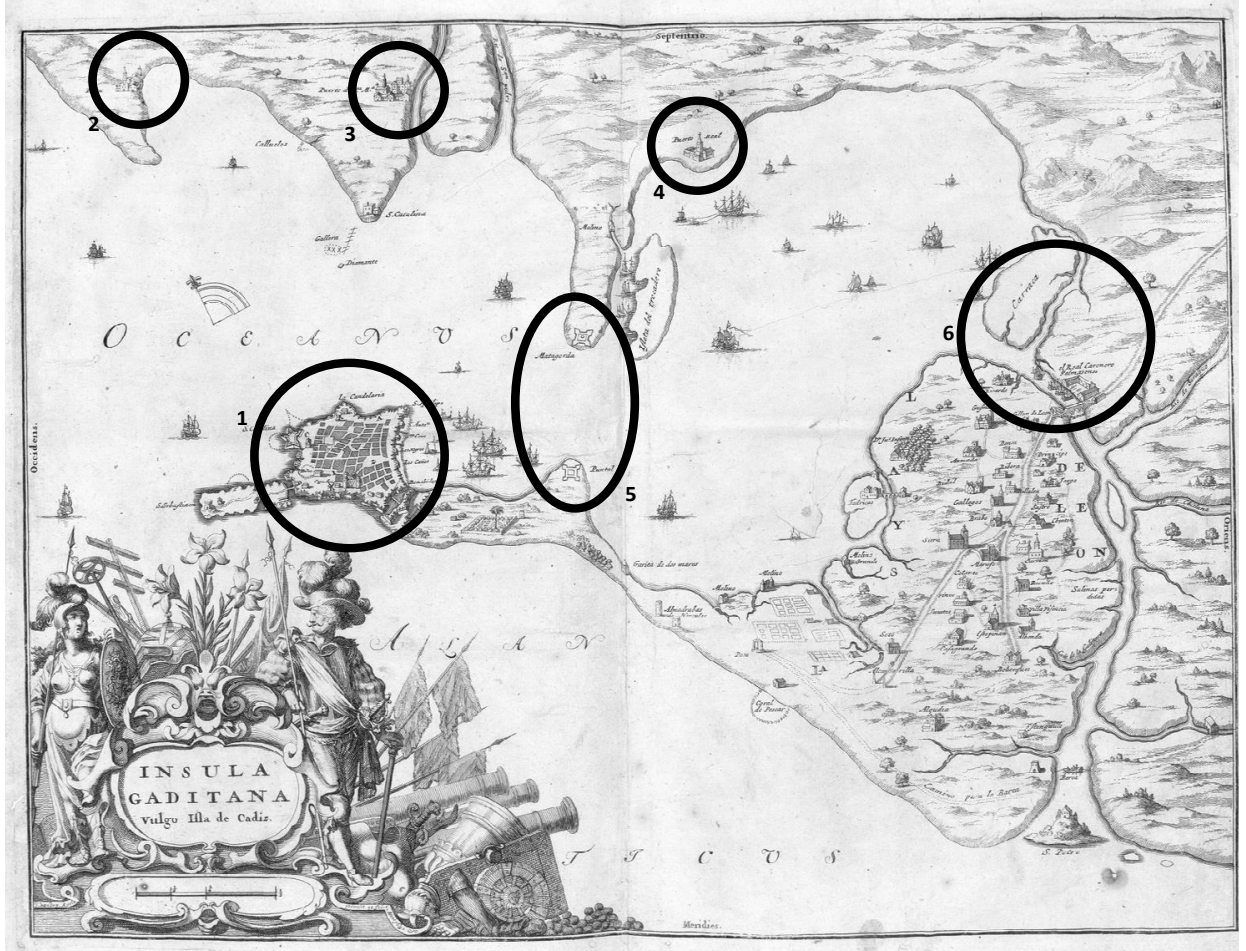

Fray Jerónimo de la Concepción, Emporio del Orbe, Cádiz ilustrada, Ámsterdam, 1690 (Biblioteca de la Universidad de Sevilla): 1. Cádiz, 2. Rota, 3. El Puerto de Santa María, 4. Puerto Real, 5. Puntales (castillos de Matagorda y El Puntal), 6. Carraca. No aparecen otras referencias importantes en los epistolarios de la Casa, como Sanlúcar, Jerez o Chipiona, más alejadas del núcleo de la bahía.

29. Para una visión histórica más integral de la bahía de Cádiz, menos centrada específicamente en la capital, véanse los excelentes trabajos de IgLesias Rodríguez, J. J.: La ciudad de Sanlúcar de Barrameda en el siglo XVIII: aspectos económicos, sociales e institucionales. Sanlúcar, 1985; Una ciudad mercantil en el siglo XVIII: El Puerto de Santa María. Sevilla, 1991; La villa de Puerto Real en la Edad Moderna (1483-1812). Málaga, 2003. 
El cuadro 2 intenta sintetizar esa información de manera útil para los objetivos presentes. Las referencias deben reducirse y, por tanto, se ha distinguido exclusivamente entre Cádiz, en relación a la capital, y la babia para englobar todas las demás poblaciones de la comarca. Sanlúcar se menciona aparte, por representar otra alternativa en la política portuaria, aglutinando tanto sus menciones documentales directas como las de Bonanza. Las cartas fechadas en barcos se han incorporado a los cómputos del puerto donde estuvieran fondeados, si en Cádiz, Sanlúcar o la bahía; y en definitiva esos son los tres conceptos con los que se ha operado.

Cuadro 2. Estancias en los «puertos» de los ministros de la Contratación

\begin{tabular}{|c|c|}
\hline 1650 & $\begin{array}{l}\text { Marqués de la Eliseda (P): } 1 \text { mes* (Cádiz, Sanlúcar); Francisco de la Parra (JO): } 5 \text { meses } \\
\text { (Cádiz) }\end{array}$ \\
\hline 1651 & $\begin{array}{l}\text { Marqués de la Eliseda (P): 5,5 meses (Cádiz, bahía, Sanlúcar); Garci Lasso de la Vega } \\
\text { (JO): } 5 \text { meses (Cádiz) }\end{array}$ \\
\hline 1652 & $\begin{array}{l}\text { Marqués de la Eliseda (P): } 8 \text { meses** (Cádiz, bahía); Fernando de Villegas (C): } 6 \text { meses* } \\
\text { (Cádiz, bahía); Garci Lasso de la Vega (JO): } 6 \text { meses (Cádiz) }\end{array}$ \\
\hline 1653 & -- \\
\hline 1654 & $\begin{array}{l}\text { Marqués de la Eliseda (P): } 5 \text { meses* (Cádiz); Lorenzo Andrés García (VA): 6,5 meses* } \\
\text { (Cádiz, bahía, Sanlúcar); José Campero de Sorrevilla (F): } 2 \text { meses (Cádiz, bahía, Sanlúcar) }\end{array}$ \\
\hline 1655 & Lorenzo Andrés García (VA): 12 meses (Cádiz, bahía, Sanlúcar) \\
\hline 1656 & Lorenzo Andrés García (VA): 9 meses* (Cádiz, bahía) \\
\hline 1657 & Lorenzo Andrés García (VA): 12 meses (Cádiz, bahía) \\
\hline 1658 & $\begin{array}{l}\text { Lorenzo Andrés García (VA): 5,5 meses* (Cádiz, bahía); Jerónimo Ladrón de Cegama } \\
\text { (F): } 4 \text { meses (Cádiz, bahía) }\end{array}$ \\
\hline 1659 & $\begin{array}{l}\text { Jerónimo Ladrón de Cegama (F): 10,5 meses (Cádiz); Antonio de Salinas (Fi): } 3 \text { meses* } \\
\text { (Cádiz) }\end{array}$ \\
\hline 1660 & $\begin{array}{l}\text { Diego de Espejo Maldonado (JO): } 8 \text { meses (Cádiz, bahía); José de Fuentes (VN): 2,5 } \\
\text { meses (Sanlúcar, Cádiz); Antonio de Salinas (Fi): } 6 \text { meses* (Cádiz) }\end{array}$ \\
\hline 1661 & Antonio de Salinas (Fi): 12 meses** (Cádiz); José de Veitia Linaje (T): 1,5 meses (Cádiz) \\
\hline 1662 & José de Veitia Linaje (T): 10,5 meses (Cádiz, bahía) \\
\hline 1663 & $\begin{array}{l}\text { Sebastián Infante (P): } 4 \text { meses (Cádiz); Bernabé Ochoa de Chinchetru: } 9 \text { meses (Cádiz, } \\
\text { bahía); José de Fuentes (VN): } 1 \text { mes (Sanlúcar) }\end{array}$ \\
\hline 1664 & $\begin{array}{l}\text { Bernabé Ochoa de Chinchetru (PA): 7,5 meses (Cádiz, Sanlúcar, bahía); Garci Lasso de } \\
\text { la Vega (JO): } 6 \text { meses (Sanlúcar, Cádiz) }\end{array}$ \\
\hline 1665 & Garci Lasso de la Vega (JO): 8 meses (Sanlúcar, Cádiz, bahía) \\
\hline
\end{tabular}


JOSÉ MANUEL DÍAZ BLANCO

ANTES DE 1717: LA CASA DE LA CONTRATACIÓN EN EL CÁDIZ DEL SEISCIENTOS

\begin{tabular}{|c|c|}
\hline 1666 & Fernando de Villegas (C): 7 meses (Cádiz, Sanlúcar) \\
\hline 1667 & $\begin{array}{l}\text { Marqués de Fuente el Sol (P): } 3 \text { meses* (Sanlúcar, Cádiz); Bernabé Ochoa de Chinchetru } \\
\text { (PA): } 5 \text { meses* (Sanlúcar); Fernando de Villegas (C): } 2 \text { meses (Cádiz) }\end{array}$ \\
\hline 1668 & $\begin{array}{l}\text { Bernabé Ochoa de Chinchetru (PA): 6,5 meses (Sanlúcar, Cádiz); Lorenzo Andrés } \\
\text { García (VA): } 2 \text { meses* (Cádiz) }\end{array}$ \\
\hline 1669 & $\begin{array}{l}\text { Bernabé Ochoa de Chinchetru (PA): } 5,5 \text { meses (Sanlúcar, Cádiz); Alonso de Baeza y } \\
\text { Mendoza (teniente de F): } 3 \text { meses* (Sanlúcar) }\end{array}$ \\
\hline 1670 & $\begin{array}{l}\text { Alonso de Baeza y Mendoza (teniente de F): } 7 \text { meses (Sanlúcar, Cádiz); marqués de } \\
\text { Fuente el Sol (P): } 1 \text { mes (Cádiz); Francisco de Alberro (CC): } 2 \text { meses* (Cádiz). }\end{array}$ \\
\hline 1671 & Francisco de Alberro (CC): 12 meses (Cádiz, Sanlúcar) \\
\hline 1672 & $\begin{array}{l}\text { Gonzalo Fernández de Córdoba (P): } 2,5 \text { meses (Cádiz, Sanlúcar); Francisco de Alberro } \\
\text { (CC): } 2 \text { meses (Cádiz); Juan Tello de Guzmán y Medina: } 2 \text { meses (Cádiz) }\end{array}$ \\
\hline 1673 & $\begin{array}{l}\text { Gonzalo Fernández de Córdoba (P): } 6 \text { meses (Cádiz, bahía); Juan Tello de Guzmán } \\
\text { y Medina (teniente de C): } 9 \text { meses (Cádiz, bahía, Sanlúcar); Pedro José de Velázquez } \\
\text { (AM): } 3,5 \text { meses (Cádiz, bahía) }\end{array}$ \\
\hline 1674 & $\begin{array}{l}\text { Gonzalo Fernández de Córdoba (P): } 4 \text { meses (Sanlúcar, Cádiz, bahía); José Sánchez de } \\
\text { Berrospe (JO): } 1 \text { mes* (bahía): Juan Tello de Guzmán y Medina (teniente de C): } 1,5 \text { meses } \\
\text { (Sanlúcar, bahía); Alonso de Baeza y Mendoza (teniente de F): } 1 \text { mes (Sanlúcar); José de } \\
\text { Fuentes (JO): } 2,5 \text { meses* (Cádiz, Sanlúcar); Juan Ignacio de Trujillo (Fi): } 1 \text { mes (Cádiz) }\end{array}$ \\
\hline 1675 & $\begin{array}{l}\text { Gonzalo Fernández de Córdoba (P): } 8 \text { meses (Cádiz, bahía); José Sánchez de Berrospe } \\
\text { (JO): 2,5 meses* (Cádiz, Sanlúcar, bahía); José de Fuentes (JO): } 3 \text { meses (Cádiz, Sanlúcar) }\end{array}$ \\
\hline 1676 & $\begin{array}{l}\text { Gonzalo Fernández de Córdoba (P): } 3,5 \text { meses** (Bahía, Cádiz, Sanlúcar); José Sánchez } \\
\text { de Berrospe (JO): 3,5 meses (Sanlúcar, Cádiz); Juan Ignacio de Trujillo (Fi): 3,5 meses } \\
\text { (Sanlúcar, bahía); José de Fuentes (JO): } 5 \text { meses (Bahía, Sanlúcar, Cádiz) }\end{array}$ \\
\hline 1677 & $\begin{array}{l}\text { Juan Jiménez de Montalvo (P): 6,5 meses (Cádiz, bahía); José Bernardo de la Parra (F): } \\
2 \text { meses* (Cádiz); Juan Ignacio de Trujillo (Fi): } 1 \text { mes (Sanlúcar, Cádiz, bahía); José de } \\
\text { Fuentes (T): } 3,5 \text { meses (Cádiz, bahía) }\end{array}$ \\
\hline 1678 & $\begin{array}{l}\text { Juan Jiménez de Montalvo (P): } 4 \text { meses (Cádiz, bahía); Juan Ignacio de Trujillo (Fi): } 2 \\
\text { meses* (Cádiz); Francisco Lorenzo de San Millán (JO): 4,5 meses (Cádiz) }\end{array}$ \\
\hline 1679 & -- \\
\hline 1680 & $\begin{array}{l}\text { Juan Jiménez de Montalvo (P): 2,5 meses (Cádiz); Juan Bruno Tello de Guzmán (teniente } \\
\text { de C): } 7 \text { meses (Cádiz) }\end{array}$ \\
\hline 1681 & $\begin{array}{l}\text { Juan Jiménez de Montalvo (P): } 2 \text { meses (Cádiz, bahía y Sanlúcar); Juan Bruno Tello de } \\
\text { Guzmán (teniente de C): } 2 \text { meses (Cádiz, bahía y Sanlúcar); Juan Ignacio de Trujillo } \\
\text { (JL): } 6 \text { meses (Cádiz, Sanlúcar y bahía) }\end{array}$ \\
\hline 1682 & $\begin{array}{l}\text { Juan Jiménez de Montalvo (P): } 4 \text { meses (Cádiz); Andrés Rubio de Sotomayor (JO): } 5 \\
\text { meses (Cádiz); Francisco Lorenzo de San Millán (JO): 4,5 meses (Cádiz) }\end{array}$ \\
\hline 1683 & $\begin{array}{l}\text { Juan Jiménez de Montalvo (P): } 2 \text { meses (Cádiz); Francisco Lorenzo de San Millán (JO): } \\
12 \text { meses (Cádiz y bahía) }\end{array}$ \\
\hline 1684 & $\begin{array}{l}\text { Pedro de Oreitia (P): } 4 \text { meses (Cádiz, bahía); Francisco Lorenzo de San Millán (JO): } \\
10 \text { meses (Cádiz, bahía) }\end{array}$ \\
\hline
\end{tabular}

Ediciones Universidad de Salamanca /

Stud. his., H. ${ }^{a}$ mod., 39, n. 2 (2017), pp. 27-52 
JOSÉ MANUEL DÍAZ BLANCO

ANTES DE 1717: LA CASA DE LA CONTRATACIÓN EN EL CÁDIZ DEL SEISCIENTOS

\begin{tabular}{|c|c|}
\hline 1685 & $\begin{array}{l}\text { Pedro de Oreitia (P): } 6 \text { meses (Cádiz y Bahía); Francisco Lorenzo de San Millán (JO): } \\
6 \text { meses (Cádiz) }\end{array}$ \\
\hline 1686 & Pedro de Oreitia (P): 6 meses (Cádiz); José de Fuentes (T): 10 meses (Cádiz, bahía) \\
\hline 1687 & $\begin{array}{l}\text { Conde de la Calzada (P): 2,5 meses (Cádiz); Francisco Lorenzo de San Millán (JO): } 12 \\
\text { meses (Cádiz) }\end{array}$ \\
\hline 1688 & $\begin{array}{l}\text { Conde de la Calzada (P): 4,5 meses* (Cádiz, bahía, Sanlúcar); Francisco Lorenzo de San } \\
\text { Millán (JO): } 12 \text { meses (Cádiz, Sanlúcar, bahía) }\end{array}$ \\
\hline 1689 & $\begin{array}{l}\text { Conde de la Calzada (P): } 8 \text { meses (Cádiz, Sanlúcar); Francisco Lorenzo de San Millán } \\
\text { (JO): } 10 \text { meses* (Cádiz) }\end{array}$ \\
\hline 1690 & 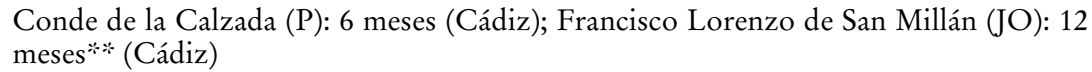 \\
\hline 1691 & 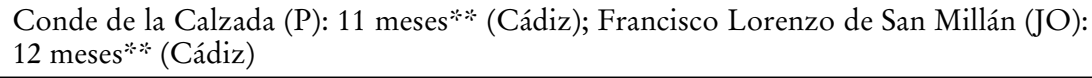 \\
\hline 1692 & $\begin{array}{l}\text { Marqués de Canales (P): } 3 \text { meses (Cádiz); Francisco Lorenzo de San Millán (JO): } 12 \\
\text { meses** (Cádiz); Juan Bautista de Aguinaga (RA): } 6 \text { meses (Cádiz) }\end{array}$ \\
\hline 1693 & $\begin{array}{l}\text { Conde de Montellano (P): } 2 \text { meses (Cádiz); Francisco Lorenzo de San Millán: } 12 \text { meses } \\
\text { (Cádiz); Juan Bautista de Aguinaga (RA): } 2 \text { meses (Cádiz) }\end{array}$ \\
\hline 1694 & $\begin{array}{l}\text { Conde de Montellano (P): } 7,5 \text { meses (Cádiz); Francisco Lorenzo de San Millán (JO): } 12 \\
\text { meses (Cádiz); Juan Bautista de Aguinaga (RA): 1,5 meses* (Cádiz) }\end{array}$ \\
\hline 1695 & $\begin{array}{l}\text { Conde de Montellano (P): } 3 \text { meses* (Cádiz); Juan Bautista de Aguinaga (RA): } 9 \text { meses } \\
\text { (Cádiz); Francisco Lorenzo de San Millán (JO): } 1 \text { mes* }\end{array}$ \\
\hline 1696 & $\begin{array}{l}\text { Marqués de Narros (P): } 8 \text { meses** (Cádiz); Juan Bautista de Aguinaga (RA): } 11 \text { meses* } \\
\text { (Cádiz) }\end{array}$ \\
\hline 1697 & $\begin{array}{l}\text { Marqués de Narros (P): 7,5 meses** (Cádiz); Juan Bautista de Aguinaga (RA): } 11 \\
\text { meses** (Cádiz) }\end{array}$ \\
\hline 1698 & $\begin{array}{l}\text { Marqués de Narros (P): } 8 \text { meses** (Cádiz); Juan Bautista de Aguinaga (RA): } 12 \text { meses*** } \\
\text { (Cádiz, bahía) }\end{array}$ \\
\hline 1699 & -- \\
\hline 1700 & -- \\
\hline
\end{tabular}

Nota: (AM): alguacil mayor; (C): contador; (CC): contador de cuentas de la Contaduría de Averías; (F): factor; (Fi): fiscal; (JL): juez letrado; (JO): juez oficial; (P): presidente; (PA): proveedor de armadas; (RA): receptor de la avería; (T): tesorero; (VA): veedor de armadas; (VN): visitador de naos. * Cálculo probablemente infravalorado. ** Continúa el siguiente año.

Fuente: AGI, Contratación, legs. 5.121-5.143.

No es posible mensurar con exactitud la cantidad de tiempo invertido en los puertos de Cádiz por los ministros de Sevilla a través de los datos del cuadro 2. Ni siquiera por aproximación. Entre otras cosas, porque no cuenta la miríada de visitas que duraban unos pocos días o semanas. Lo que podemos ofrecer no es sino 
un reflejo pálido de esta presencia institucional, apenas atento a los aspectos más llamativos. Por otro lado, tampoco se pretende ningún tipo de nitidez cuantitativa; tan solo un apoyo documental suficiente a una afirmación necesaria para nuestro razonamiento, la de que la actuación directa de la Casa en Cádiz era sistemática y significativa en el siglo xviI, especialmente durante su segunda mitad. En tal sentido, el cuadro 2 sí aporta una base clara y suficiente, demostrando fehacientemente que todos los años había uno o varios ministros de la Casa supervisando la actividad naval y comercial entre la desembocadura del Guadalquivir y la Isla de León.

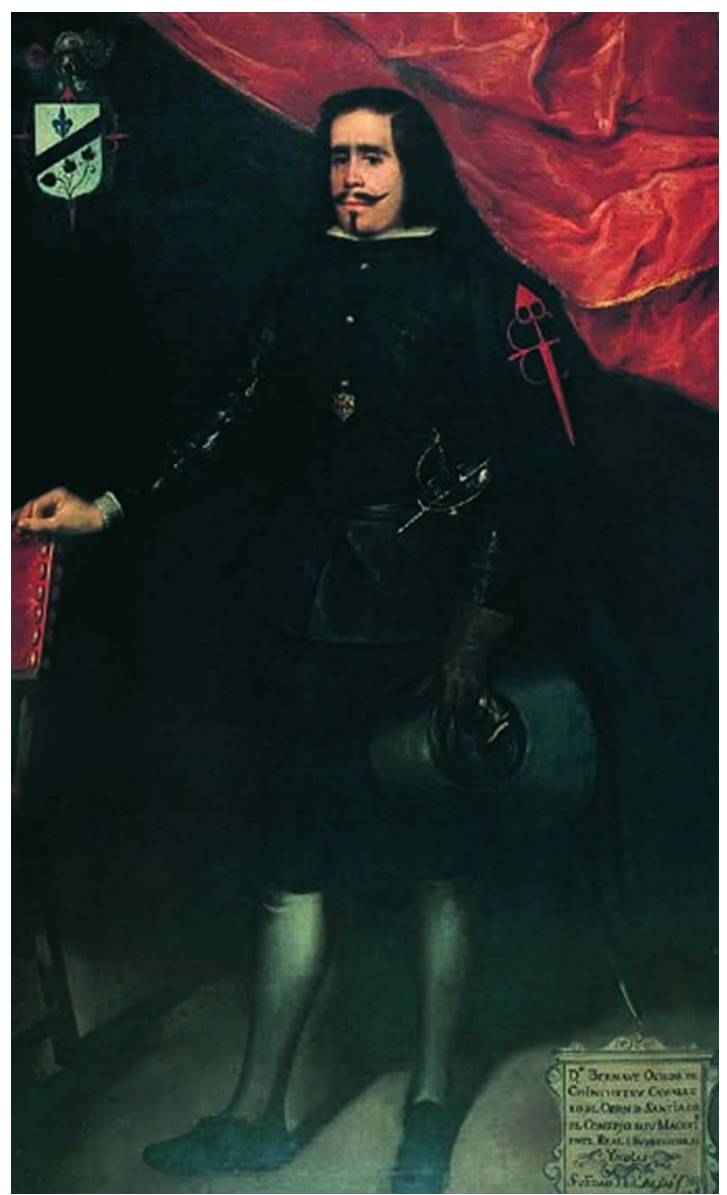

Juan de Alfaro, Don Bernabé Ochoa de Chinchetru, Museo de Bellas Artes de Córdoba. 
No solo Veitia Linaje dedicó varios meses de su vida a recorrer los paisajes gaditanos. También lo hicieron varios presidentes de la Casa, como el marqués de la Eliseda, Gonzalo Fernández de Córdoba, Juan Jiménez de Montalvo o el conde de la Calzada, entre otros ${ }^{30}$. O ministros de tanto peso institucional como factores, contadores, tesoreros o sus tenientes, o los nuevos jueces oficiales, directamente nombrados como tales, si no asociaban esa condición a otros oficios que no la poseían per se, como los de receptor o contador de la avería. El proveedor de armadas Bernabé Ochoa de Chinchetru, que ahora nos contempla desde el espléndido retrato que le realizó el pintor Juan de Alfaro, paseó largamente por Cádiz, en varias estancias realizadas en la década de $1660^{31}$. Pese a la mala fama del servicio en los puertos, la labor no se dejaba en manos de oficiales de segunda fila. Conscientes de su vital importancia, lo asumían en mayor o menor medida todos los ministros que ocupaban la primera fila del poder político en la Casa de la Contratación ${ }^{32}$. He aquí, por tanto, el trasfondo histórico del capítulo octavo del Norte de la Contratación ${ }^{33}$, las disposiciones de la Recopilación y los apuntes gaditanos de Lantery.

30. Algunos datos básicos sobre ellos y sobre la mayoría de los oficiales mencionados en el cuadro 2 en los célebres apéndices de Schäfer, op. cit., I, pp. 361-370. No obstante, debe insistirse en la idea de que nos queda mucho por conocer sobre estos hombres, que en algunos casos son todavía unos completos desconocidos.

31. Museo de Bellas Artes de Córdoba: Juan de Alfaro, Don Bernabé Ochoa de Chinchetru, ¿1661 ? Sitúo entre interrogantes la datación, que es bastante confusa pese a figurar en la cartela, pues sitúa a Ochoa en el Consejo de Indias en el momento del posado y eso solo pudo suceder después de 1674, cuando el retratado abandonó la Casa de la Contratación y se mudó a Madrid para ejercer como consejero: SCHÄFER, op. cit., I, pp. 346 y 366. Es bastante probable que la cartela sea un añadido posterior y de ahí las incoherencias, pero debería estudiarse más detenidamente.

32. Veitia Linaje: Norte de la Contratación, pp. 55-56: «Debaxo de la suposicion de ser gravamen este de los turnos (aunque lo juzgan al contrario, los que lo miran de afuera) parece que deviera seguirse el estilo, que vemos generalmente practicado en los Consejos, Chancillerias, y Audiencias Reales, que es caer sobre los mas modernos, y empeçar por ellos lo que es de mayor carga, y gravamen, [...] pero tengo por cierto $q[u e]$ se fundo el origen, y principio deste estilo en la consideracion de ser tan importante que el que baxa a los Puertos estè noticioso de las ordenanças, y sabidor de los negocios [...]. Queda referido en este libro, como puede, y suele baxar el Presidente à los Puertos en ocasiones de recibos, ò despachos».

33. Capítulo octavo del libro primero, como ya se ha indicado, dedicado a las estructuras de la Casa (el segundo se centra en las de las flotas y armadas). No obstante, también se detectan algunas discrepancias puntuales. Por ejemplo, en el párrafo final del capítulo, número 21, Veitia afirma que, hallándose en Cádiz el mencionado Ochoa de Chinchetru en 1669, se decidió que Francisco de Alberro bajase a Sanlúcar para revisar los navíos mercantes. Y, como siempre, se remite a documentación que lo acredita, en este caso un acuerdo registrado en la escribanía de armadas. Sin embargo, los epistolarios demuestran que el que bajó a Sanlúcar aquel año fue Alonso de Baeza. Francisco de Alberro no abandonó Sevilla hasta un año después, de 1670 a 1672, situándose además en Cádiz antes que en Sanlúcar. 
La llamativa duración de algunas de estas residencias gaditanas desde la década de 1680 implica una cierta transformación del modelo. Eran casos que implicaban ya una vecindad no tan lejana a la que caracterizaba a los propios jueces de Cádiz. El salto cualitativo lo dio Francisco Lorenzo de San Millán, juez oficial de la Casa de la Contratación, «recto» $\mathrm{y}$ «realista» al decir de Lantery, que no permaneció en Cádiz dos, cinco o nueve meses, sino de manera continuada entre 1682 y $1694^{34}$. Inmediatamente después, el incontenible Juan Bautista de Aguinaga, receptor general de averías y juez oficial, continuó su senda. Llegó a la bahía en 1695 y lo encontramos allí hasta $1698-99^{35}$, cuando la documentación se vuelve más fragmentaria y nos impide contemplar con precisión el fin de siglo ${ }^{36}$. En todo caso, queda patente que, durante las últimas dos décadas del xvir, el servicio rotativo anual de la bajada a los puertos tendió a convertirse en un servicio permanente. Lo extraordinario tendía a convertirse en ordinario de una manera mucho más profunda de lo que implica la mera repetición cíclica y periódica. Es evidente que de forma paulatina se estaban introduciendo cambios que iban en la línea de estabilizar la presencia de la Casa en Cádiz. No sabemos con exactitud qué pensaban al respecto los jueces sevillanos; si realmente lo veían como una forma viable de compaginar la preeminencia marítima de Cádiz y el protagonismo administrativo de Sevilla o si lo aceptaban como una contemporización provisional, a la espera de que llegara el inevitable traslado final a Cádiz. Sea como fuere, asistimos a los precedentes de facto de la transformación de iure acaecida en 1717.

La realidad es siempre compleja y confusa. Rastrear líneas muy claras dentro de ella a veces es poco más que un rendido ejercicio de simplificación ${ }^{37}$. No

34. Schäfer, op. cit., I, p. 364; Bustos Rodríguez (ed.): Un comerciante saboyano, pp. 215-216, que lo nombra como Francisco Samillán.

35. Garmendia Arruebarrena, J.: Vascos en Cádiz (siglos XVII-XVIII). San Sebastián, 1986, pp. 107-112 y «Un personaje vasco en la Sevilla de mediados del XVII», Revista Internacional de Estudios Vascos, 36-1, 1991, pp. 73-78; Díaz Blanco, «Servicio al rey y progreso social...», op. cit.

36. Desgraciadamente, la mala calidad de la documentación continúa para el período 17001717. Sirva de ejemplo que todas las cartas de esa época están guardadas en un único legajo: AGI, Contratación, leg. 5.143, en el que, en cualquier caso, se detectan cartas firmadas por personajes como Aguinaga, Pablo Rubio de Sotomayor, Francisco Pablo de Pineda, Francisco de San Millán y Ceballos o, entre otros, Francisco de Varas y Valdés, antes de su etapa como presidente.

37. En este caso concreto, cualquiera que abra los legajos de la Casa de la Contratación se dará cuenta de la existencia de un microcosmos humano que, ni de lejos, queda abarcado en 
obstante, dentro del hormiguero de personas que iban y venían, apareciendo y desapareciendo, se dibujan al menos dos formas de presencia continuada de la Casa en Cádiz: la de los jueces gaditanos y las de los jueces sevillanos que bajaban a los puertos, cada vez de manera más continuada. En cierta manera, la Recopilación registra esta presencia doble como un problema sobre el que se legislaba en Madrid, donde este tipo de conflictos no extrañaban a nadie. Por un lado, se ordenaba a los jueces hispalenses que guardasen la jurisdicción de sus colegas, solicitando incluso «si fuere posible escusar el nombramiento de Comissarios, salarios, y costas» en Cádiz. Y por otro, se impelía al juez gaditano a ser tan escrupuloso a la hora de cumplir sus obligaciones como en no excederlas. Eso quería decir que debía dar cuenta a la Casa de todo aquello para lo que no estuviera habilitado, «guardandole el respeto debido». Más aun, debía ejecutar minuciosamente todos los puntos que contuvieran las visitas que la Casa le cometiera, igual que cualquier otro de los jueces que trabajaban en ella. «Y vnos, y otros», en definitiva, «tengan entre si la buena correspondencia, que conviene» ${ }^{38}$.

A esta admonición general, la Recopilación añadía otras particulares, entre las que llama la atención una ley que entraba en la convivencia entre el juez de Cádiz y el juez de Sevilla que bajaba a los puertos. La norma establecía que

se junten el dicho Iuez Oficial de Sevilla, y el de Cadiz, y no el vno sin el otro, si no fuere por enfermedad, ó otro justo impedimento, y el Iuez Oficial de Sevilla, ó persona nombrada, no pueda llevar á Cadiz Alguazil, ó Escrivano para este efecto, porque se han de hazer las diligencias ante los nombrados por el Iuez de Cádiz, y no ante otro alguno ${ }^{39}$.

Las sanciones por incumplir estas advertencias eran altas, de 100.000 maravedíes para penas de Cámara. Eso da idea de la importancia que se concedía en la Corte al mantenimiento de buenas relaciones entre los homólogos hispalenses y gaditanos, especialmente cuando tenían que coordinarse para algo tan indispensable como el funcionamiento de las flotas y armadas de la Carrera.

Inmediatamente, se viene a la mente el razonamiento de que la publicación de estas normas tenía mucho que ver con realidades cotidianas en las que se repetían

estas páginas. Hubo otros oficios de armadas que, como el de juez de Indias, implicaba una presencia mucho más continua en el litoral que en Sevilla y se detecta que la Casa estuvo en comunicación con personas establecidas en Sanlúcar de Barrameda sobre cuyos vínculos institucionales queda mucho por saber, como Francisco de Isla y Solórzano o Gabriel Maldonado de Córdoba. Son cuestiones en las que deberían entrar futuros trabajos.

38. RLRI, lib. 9, tít. 4, ley 5 (basada en una cédula de Felipe III, Lerma, 1 de mayo de 1610).

39. Idem, ley 14 (basada en dos cédulas de Felipe II, la primera en Monzón, 14 de noviembre de 1563, y la segunda en Toledo, 19 de noviembre de 1565). 
situaciones conflictivas. Algo de eso habrá que reconocer, pero con los matices convenientes. Visto a largo plazo, todo dependía mucho de las personas y de las situaciones. Muy cambiantes en el curso de las décadas, no hace falta decirlo. Pueden documentarse diversas relaciones amistosas entre jueces de Cádiz y ministros de Sevilla. Algunas de las más evidentes nos devuelven al contexto del cobro de salarios. Los gaditanos delegaban el cobro en alguna persona que viviese en Sevilla y, en más de un caso, depositaron su confianza, mucha confianza, en colegas de la Casa. Por ejemplo, el salario de Juan Bautista de Baeza lo recogió varias veces Miguel de Armora, contador-diputado de averías entre 1598 y 1605, y después Andrés de Munive, llamado a ser tesorero de la Contratación. Cuando Baeza empezó a compartir el sueldo con su hijo Francisco, Félix Escudero de Espinosa, otro contador-diputado que sirvió el oficio entre 1606 y 1634, se convirtió en su contacto habitual. De hecho, estuvo cobrando el sueldo por ellos durante casi veinte años, nada menos ${ }^{40}$.

La correspondencia que la Casa recibía desde Cádiz transluce colaboración entre los implicados. De hecho, es lo que predomina normalmente. No podemos saber si tal colaboración era más o menos gustosa. Presumiblemente, las cartas callarían muchas cosas. Pero, realmente, había coordinación. Unos y otros se las apañaban bien para preparar los convoyes del Atlántico. No obstante, resulta difícil no pensar en un aumento de las tensiones conforme avanzaba el siglo. Si se retoma la perspectiva de la representación para el cobro de salarios, llama la atención que desde mediados del xviI empiecen a aparecer nombres como los de Juan Antonio Vela, Juan de Velasco o Miguel Salvador Aldana. Para quien estudie la Casa de la Contratación, son nombres probablemente desconocidos. No pertenecían a ella, que se sepa. Solo al final del siglo reaparecen esporádicamente referencias familiares, como Juan Félix de Arriola, oficial mayor y teniente de la tesorería, o Francisco Pablo de Pineda, pagador de armadas ${ }^{41}$. Y mientras, los enfrentamientos más sonados empezaban a tomar forma.

El primero tuvo lugar durante los años 1650. Queda mucho por conocer de este interesante episodio, desafortunadamente protagonizado por la familia Fernández Moreno. Pedro Fernández Moreno ocupaba la tenencia del Juzgado por dejación de Jerónimo Rodríguez de Rozas. En 1654, fue suspendido, pero recibió el consuelo de saber que su hijo Bartolomé lo sustituiría mientras se aclaraba la situación. Lejos de eso, el problema se enervó aún más cuando Pedro murió. Bartolomé entendió que su interinidad había acabado y podía considerarse

40. AGI, Contaduría, legs. 346a, 348, 353, 355a, 356a, 358, 362a, 364; Díaz Blanco, «Servicio al rey y progreso social...», op. cit.

41. AGI, Contaduría, legs. 397, 400; Díaz Blanco, «Servicio al rey y progreso social...», op. cit. 
titular del Juzgado de Indias gaditano. La Casa no estaba de acuerdo y actuó de oficio contra él, por haber presuntamente «incurrido en graves penas y en las establecidas por leyes de estos reinos contra los que se fingen jueces sin serlo» ${ }^{42}$. El trasfondo podría encontrarse en el retorno al Juzgado de Cádiz de los Polanco, un linaje sevillano con el que tradicionalmente la Casa había mantenido estrechas relaciones. Esto se verificó en 1659, tras la muerte de Rodríguez de Rozas, aunque finalmente tuvo un recorrido muy escaso. En cualquier caso, todo indica que los Fernández Moreno padecieron un auténtico calvario. Mientras se aferraban al ejercicio del cargo en los años 50, se les denegó el cobró del salario, que no pudieron empezar a recibir hasta después de 1670 , cuando ya habían quedado definitivamente apartados del $\operatorname{cargo}{ }^{43}$.

Esta primera ruptura solo fue un aperitivo de lo que vino poco después: el pulso por desmontar el Juzgado y la Tabla de Indias de Cádiz que tuvo lugar entre 1664 y 1679. La Casa de la Contratación (quiere decirse, sus ministros en Sevilla) se destacó en la causa. Cuando el Consejo de Indias solicitó información por primera vez sobre estos temas, preocupado por el incremento del fraude en el ámbito de la bahía de Cádiz, la Casa respondió antes que nadie con evidentes intenciones de desmontar las instituciones gaditanas que, tras la defenestración de los Fernández Moreno, los Polanco habían abandonado en manos de Pedro Jiménez de Guzmán. La carta es notablemente interesante, porque incluía una historia del Juzgado de Indias que pretendía justificar la posición defendida por la Casa. Según esa narración, los órganos de poder gaditanos se fundaron para gestionar el tercio de frutos reconocido a los vecinos de Cádiz, El Puerto y Jerez. Sin embargo, los jueces de la Contratación argumentaban que el tercio había dejado de existir, dado que la reserva ya no se aprovechaba para cargar productos agrícolas, sino manufacturas extranjeras. Por tanto, ¿qué razón de ser podía esgrimir aún el Juzgado de Indias gaditano? La respuesta que se deducía era evidente: ninguna, y daba paso así al esperado dictamen final ${ }^{44}$.

Esta carta no era importante solo porque abriera la vía que llevó a la anulación del Juzgado de Indias en $1666^{45}$. También resulta apasionante vincular la

42. AGI, Contratación, leg. 5.742. Por cierto, el responsable de la denuncia era el fiscal Antonio de Salinas, a quien los epistolarios de la Casa sitúan en Cádiz justo en esas fechas finales de los años 50 (ver cuadro 2).

43. La correspondencia de entrada de la Casa prueba la actividad de Bartolomé Fernández Moreno en los años 50: AGI, Contratación, legs. 5.122 y 5.123. Respecto a los retrasos en el cobro salarial: AGI, Contaduría, legs. 379, 384a y 386a.

44. AGI, Indiferente General, leg. 633; la Casa a Felipe IV, Sevilla, 28 de octubre de 1664. Díaz Blanco: Asi trocaste tu gloria..., op. cit., p. 233 y ss.

45. AGI, Contratación, leg. 5.039; real cédula, Madrid, 6 de septiembre de 1666. 
reconstrucción histórica que presentaba con la actividad investigadora de José de Veitia Linaje, que entonces era juez oficial tesorero de la Casa. Por tanto, la carta puede ponerse en relación con las teorías que finalmente vieron la luz en 1672, en el capítulo XXV del Norte de la Contratación. La obra de Veitia era cualquier cosa menos inocente o neutral, y con razón se ha visto en ella una abierta defensa de la versión más restringida del monopolio sevillano frente al avance de posiciones gaditano ${ }^{46}$. El capítulo Del Inez, y Iuzgado de Indias de la Ciudad de Cadiz expresaba los polémicos puntos de vista. Veitia entendía que la anulación de 1666 significaba la culminación de largos esfuerzos y deliberaciones, que documentaba con su proverbial erudición documental. La ensalzaba como una decisión sabia y conveniente $y$, sin morderse la lengua, pregonaba su satisfacción «si permanece la resolución, que vltimamente se tomò [...] mandando extinguir absolutame, y remotamente el Iuzgado, y la tabla de Indias de la Ciudad de Cadiz» ${ }^{47}$.

El condicional de Veitia no permaneció incólume mucho tiempo. A fines de los 70 la situación se revertió ${ }^{48}$. La Recopilación recogió la noticia completamente al límite. Ultimada y publicada en 1680, el título dedicado al juez de Cádiz finalizaba con una nota en la que se advertía que el cese de jurisdicción resuelto por Mariana de Austria en cédula de 6 de septiembre de 1666 se había anulado por otra de 23 de septiembre de 1679, «á instancia, y suplicación de la Ciudad de Cadiz, por hazerle merced, y haver servido con 80.250 escudos de á 10 reales» ${ }^{49}$. ¿Terminaron aquí los conflictos entre la Casa y el Juzgado gaditano? Ciertamente, no se conocen otros episodios llamativos como los anteriormente descritos durante el período 1680-1700. No obstante, eso no tiene por qué significar el cierre de las tensiones. Tal vez, sencillamente, la competición cambió y se hizo más soterrada. Recordemos que fue entonces, hacia 1680, cuando las estancias gaditanas se volvieron estables. ¿Es casual esta secuencia cronológica o encierra algún tipo de relación causa-efecto? ¿El asentamiento de los jueces que bajaban a los puertos pretendió opacar al juez de Cádiz, Pedro de Román y Soto, ante el fracaso de la anterior estrategia y la evidencia del protagonismo gaditano en la Carrera de Indias?

$* * *$

46. García-Baquero González, A.: "Cádiz y su Tercio de Toneladas en las flotas de Indias: contribución al estudio de la pugna Sevilla-Cádiz en el interior del complejo monopolístico andaluz», Gades, 1, 1978, pp. 107-120.

47. Veitia Linaje, Norte de la Contratación..., op. cit., p. 188. Nuevamente la paginación y el número del capítulo son los del libro primero de la obra.

48. AGI, Contratación, leg. 5.050; real cédula, Madrid, 23 de septiembre de 1679.

49. RLRI, III, fol. 161v. 
Estas páginas comenzaron evocando la importancia del año 1717 y la oportunidad de insertarlo dentro de un esquema interpretativo que explicase la basculación comercial y marítima entre Sevilla y Cádiz durante los siglos xvir y xviII. A la luz de los acontecimientos que hemos expuesto, y de otros que la investigación irá desvelando en fechas futuras, puede concluirse la inexactitud de excluir a las instituciones del amanecer gaditano en el Seiscientos. No se puede afirmar que solo los comerciantes y los marineros participaran de este momento. Los ministros y oficiales de la Contratación también estuvieron allí, aunque en muchos casos fuera a regañadientes. Así que, al valorar 1717 como la fecha del traslado a Cádiz, deberemos recordar que la Casa ya llevaba mucho tiempo protagonizando una extraña suerte de traslado progresivo.

En cierta manera, siempre había estado presente en Cádiz a través de los jueces de Indias, instalados ya en el siglo xvi. Después, en el xvir, la presencia no hizo más que incrementarse y tornarse más compleja, con la continua llegada de ministros sevillanos, primero anualmente y desde 1680 de forma más estable. Por tanto, ¿qué significa decir que la Casa se trasladó a Cádiz en 1717? Básicamente, que la sede central oficial cambió. La efeméride se entiende mejor como un hito significativo en el interior de procesos históricos más prolongados, relativos a la competencia portuaria entre dos ciudades de una región estratégicamente conectada con las rutas del comercio global. Antes que por ser un hecho aislado, el impacto de 1717 radica en haber culminado las tendencias de desplazamiento institucional latentes durante el Xvir, inaugurando una época en la cual la sede principal de la Casa sería el fascinante Cádiz dieciochesco.

Sin embargo, en la ciudad ilustrada la Casa ejerció una influencia menos destacada que en la Sevilla de los Austrias. Los especialistas nos han enseñado que el comercio gaditano se hallaba menos moldeado por las instituciones monárquicas y que, en todo caso, surgieron otras -la Intendencia General de Marina o el Juzgado de Arribadas- que opacaron a la Casa y le arrebataron sus funciones, conforme el modelo comercial comenzaba a adquirir una fisonomía distinta con la desaparición del sistema de flotas y armadas o la publicación de los decretos de Libre Comercio. Así hasta que en 1790 la Casa cerró sus puertas definitivamente, en reconocimiento último de su decadencia ${ }^{50}$. Bajo esta luz, me atrevería a cerrar estas reflexiones con una pregunta que quizás no sea completamente impertinente:

50. Entre la crecida bibliografía, véase García-BAQuero GonzÁlez: La Carrera de Indias; Bustos Rodríguez: Cádiz en el sistema atlántico; Bernal, A. M.: España, proyecto inacabado. Costes/beneficios del imperio. Madrid, 2005; Delgado Ribas, J. M.: Dinámicas imperiales (1650-1796). España, América y Europa en el cambio institucional del sistema comercial español. Barcelona, 2007. 
JOSÉ MANUEL DÍAZ BLANCO

ANTES DE 1717: LA CASA DE LA CONTRATACIÓN EN EL CÁDIZ DEL SEISCIENTOS

¿cuándo fue más útil para Cádiz la Casa de la Contratación, en el siglo xvir o en el xviII? ¿Antes de 1717 o después? Tal vez la respuesta sea la que parece más obvia. O tal vez no.

\section{BibLIOGRAFÍA}

Andújar Castillo, F:: «La Casa de Contratación y la venalidad de los cargos (1634-1717)», en NúÑEz, F. y Gamero, M. (coords.): Entre lo real y lo imaginario. Sevilla, U. de Sevilla-U. de Huelva, 2014, pp. 47-73.

Bernal, A. M.: España, proyecto inacabado. Costes/beneficios del imperio. Madrid, Marcial Pons, 2005.

Bustos Rodríguez, M.: Cádiz en el sistema atlántico. La ciudad, sus comerciantes y la actividad mercantil (1650-1830). Madrid, Sílex, 2005.

Bustos Rodríguez, M.: «Cambio político y comunidades mercantiles: los flamencos de Cádiz tras la Paz de Utrecht», en Iglesias Rodríguez, J. J. y García Bernal, J. (coords.): Andalucía en el mundo atlántico. Agentes y escenarios. Madrid, Sílex, 2016, pp. 311-333.

Bustos Rodríguez, M. (ed.): Un comerciante saboyano en el Cádiz de Carlos II (Las memorias de Raimundo de Lantery, 1673-1700). Cádiz, Caja de Ahorros, 1983.

Carrasco González, G.: Los instrumentos del comercio colonial en el Cádiz del siglo XVII (1650-1700). Madrid, Banco de España, 1996.

Carrasco González, G.: Comerciantes y casas de negocios en Cádiz (1650-1700). Cádiz, Universidad, 1997.

Céspedes del Castillo, G.: La avería en el comercio de Indias. Sevilla, EEHA, 1945.

Concepción, J. de la: Emporio del Orbe, Cádiz ilustrada. Ámsterdam, Juan Bus, 1690.

Delgado Ribas, J. M.: Dinámicas imperiales (1650-1796). España, América y Europa en el cambio institucional del sistema comercial español. Barcelona, Bellaterra, 2007.

Díaz Blanco, J. M.: Así trocaste tu gloria. Guerra y comercio colonial en la España del siglo XVII. Madrid, IUHS-Marcial Pons, 2012.

DíAz BLANCo, J. M.: «Servicio al rey y progreso social en el siglo xvir: los oficiales de la avería en la Casa de la Contratación», en García Hernán, E. y Maffi, D. (coords.): Estudios sobre guerra y sociedad en la Monarquía Hispánica. Guerra marítima, estrategia, organización y cultura militar (1500-1700). Valencia, Albatros, 2017.

Domínguez Ortiz, A.: Orto y ocaso de Sevilla. Sevilla, Universidad, 1991 [1946].

Domínguez OrTiz, A.: «La burguesía gaditana y el comercio de Indias desde mediados del siglo xvir hasta el traslado de la Casa de Contratación», en La burguesía mercantil gaditana (1650-1868). Cádiz, Instituto de Estudios Gaditanos, 1976, pp. 3-11.

García-Baquero González, A.: La Carrera de Indias: suma de la contratación y océano de negocios. Sevilla, Algaida, 1992.

García-Baquero González, A.: «Cádiz y su Tercio de Toneladas en las flotas de Indias: contribución al estudio de la pugna Sevilla-Cádiz en el interior del complejo monopolístico andaluz», Gades, 1, 1978, pp. 107-120. 
Garmendia Arruebarrena, J.: Vascos en Cádiz (siglos XVII-XVIII). San Sebastián, Fundación Kutxa, 1986, pp. 107-112.

Garmendia Arruebarrena, J.: «Un personaje vasco en la Sevilla de mediados del XviI», Revista Internacional de Estudios Vascos, 36-1, 1991, pp. 73-78.

GIRARD, A.: La rivalidad comercial y marítima entre Sevilla y Cádiz hasta finales del siglo XVIII. Antonio García-Baquero, ed., Sevilla, Renacimiento, 2006 [1932].

Haring, C. H.: Comercio y navegación entre España y las Indias. México, FCE, 1979 [1918].

Herrero Gil, M. D.: El mundo de los negocios de Indias. Las familias Álvarez Campana y Llano San Ginés en el Cádiz del siglo XVIII. Sevilla, Diputación-Universidad, CSIC, 2013.

Iglesias Rodríguez, J. J.: La ciudad de Sanlúcar de Barrameda en el siglo XVIII: aspectos económicos, sociales e institucionales. Sanlúcar, Ayuntamiento, 1985.

Iglesias Rodríguez, J. J.: Una ciudad mercantil en el siglo XVIII: El Puerto de Santa María. Sevilla, Muñoz Moya y Montraveta, 1991.

Iglesias Rodríguez, J. J.: La villa de Puerto Real en la Edad Moderna (1483-1812). Málaga, Fundación Unicaja, 2003.

Iglesias, J. J. y López-Guadalupe, M. L. (coords.): Realidades conflictivas. Andalucía y América en la España del Barroco. Sevilla, Universidad, 2012.

Lozano Navarro, J. y Castellano, J. L. (coords.): Violencia y conflictividad en el universo barroco. Granada, Comares, 2010.

Pardo Molero, J. F. y Lomas Cortés, M. (coords.): Oficiales reales. Los ministros de la Monarquía Católica. Valencia, Universidad, 2012.

Recopilación de Leyes de los Reinos de Indias. México, Porrúa, 1987 [1681].

Schäfer, E.: El Consejo Real y Supremo de las Indias. Historia y organización del Consejo $y$ de la Casa de Contratación de las Indias. Valladolid, Junta de Castilla y León, 2003 [1935-47].

Schulte, R. y Tippelskirch, X. V. (eds.): Reading, Interpreting and Historicizing: Letters as Historical Sources. Florencia, EUI Working Paper, 2004.

Teijeiro, J. M.: Cargadores de Indias y marinos. Los La Rosa. Cádiz, Quorum, 2005.

Veitia Linaje, J. de: Norte de la Contratación de las Indias Occidentales. Sevilla, Juan Francisco de Blas, 1672. 